Chapter 11

\title{
Innovative Strategies for Tissue Engineering
}

\author{
Juliana Lott Carvalho, Pablo Herthel de Carvalho, \\ Dawidson Assis Gomes and \\ Alfredo Miranda de Goes
}

Additional information is available at the end of the chapter

http://dx.doi.org/10.5772/53337

\section{Introduction}

Unmet need. It is beyond dispute that human population is ageing. For the first time in history, people age 65 and over will outnumber children under age 5 . This trend is emerging around the globe, and will bring several challenges for health technologies. For instance, in a few decades, the loss of health and life worldwide will be greater from chronic diseases than from infectious diseases and accidents [4].

The report made by the National Institute of Health and the National Institute of Aging (NIH/ NIA) underscores the unmet needs lying ahead for regenerative medicine. Chronic diseases, in opposition to infectious diseases, are mainly treated by regenerative approaches, instead of immunization and antibiotics.

Actually, many of those challenges are already present in our daily living: malformations [9,14], accidents [16], chronic infections [9,15], and end-organ failure [17] (usually occurs during the final stages of degenerative and other diseases), may, in some cases, only be treated by organ replacement. In fact, end-organ failure alone already affects millions of Americans. More specifically, nearly six million Americans suffer from heart failure with approximately 550,000 new cases diagnosed annually, 530,000 Americans suffer from end-stage renal disease and nearly 25 million Americans suffer from chronic obstructive pulmonary disease with an estimated 12 million new annual diagnoses [5]. As already stated, for many of those patients, organ transplantation is their only treatment option. Currently, organ transplantation is considered the best option for some patients and achieves up to $98,5 \%$ of patient 1 -year survival rates [18]. Unfortunately, though, current organ shortage/recovering engenders waiting lines of up to three or more years [5]. During 2008, for instance, the number of heart transplantations 
decreased 2,67\%, even though waiting lines increased during the same year. Such decrease occurred mainly due to a reduction in number of recovered organs [18].

It is clear that alternatives to organ transplantation need to be developed as soon as possible. That's where tissue engineering comes into picture.

Tissue engineering. Tissue engineering refers to an "interdisciplinary field that applies the principles of engineering and the life sciences toward the development of biological substitutes that restore, maintain, or improve tissue function" [3]. The term was first coined by Dr. Fung, from California University, which suggested this name during the National Science Foundation Meeting, in 1987 [2]. The first official definition dates to 1988, though, when Skalak and Fox published it after the "Tissue engineering Meeting" held in Lake Tahoe, USA during that year [1].

In 1993, Langer and Vacanti described three strategies for the creation of new tissue in vitro [3].

1. Isolated cells or substitutes. The concept of treating injured tissues with isolated cells is currently regarded as cell therapy. Infusion of cells, e.g. stem cells, has presented several promising results, and have already been approved for human use for specific applications [21] but in some cases, is hindered by the lack of fixation of cells in the site of lesion. When injected systemically, stem cells are attracted to injured tissues, but are also found in several organs such as lungs, liver and spleen [56].

2. Tissue inducing substances. At the time, tissue inducing substances included growth factors, small molecules, and other classes of molecules which, if delivered in the organism, would promote several effects on cells, such as growth [58], survival [58], migration [57] and neo tissue formation.

3. Cells placed on or within matrices. Associated cells and substrates provide the injured tissue with continuity, and promotes cell attachment and fixation. In this context, scaffolds may be associated with inducing substances, providing means to combine all the aforementioned strategies. The combination of cells and matrices, in addition to inducing substances or not, is currently the main strategy for tissue engineering, as depicted in Figure 1.

Currently, tissue engineering focuses mainly of associating cells with supports (also called biomaterials or scaffolds), in order to: i. promote cell attachment and restrict their distribution in the tissue, ii. direct cell distribution and differentiation, iii. sustain large tissue losses while new tissue is formed, and ultimately, to iv. lead to new tissue formation.

Since its early days, tissue engineering has significantly evolved in each of its pillars - Cells, signaling molecules and scaffolds. This evolution covered both conceptual aspects - as evidenced above - as well as practical aspects, mainly reflected in the achievements of the field (for more information, go to conclusion section). Unfortunately, even though cells and signaling molecules platforms have evolved during the past decades, leading to major field evolution, the degree of success of tissue engineering methods is still highly dependent on the properties of the scaffold. Therefore, this study focuses on the main Achille's Hill of tissue engineering: production of scaffolds for biological applications. 


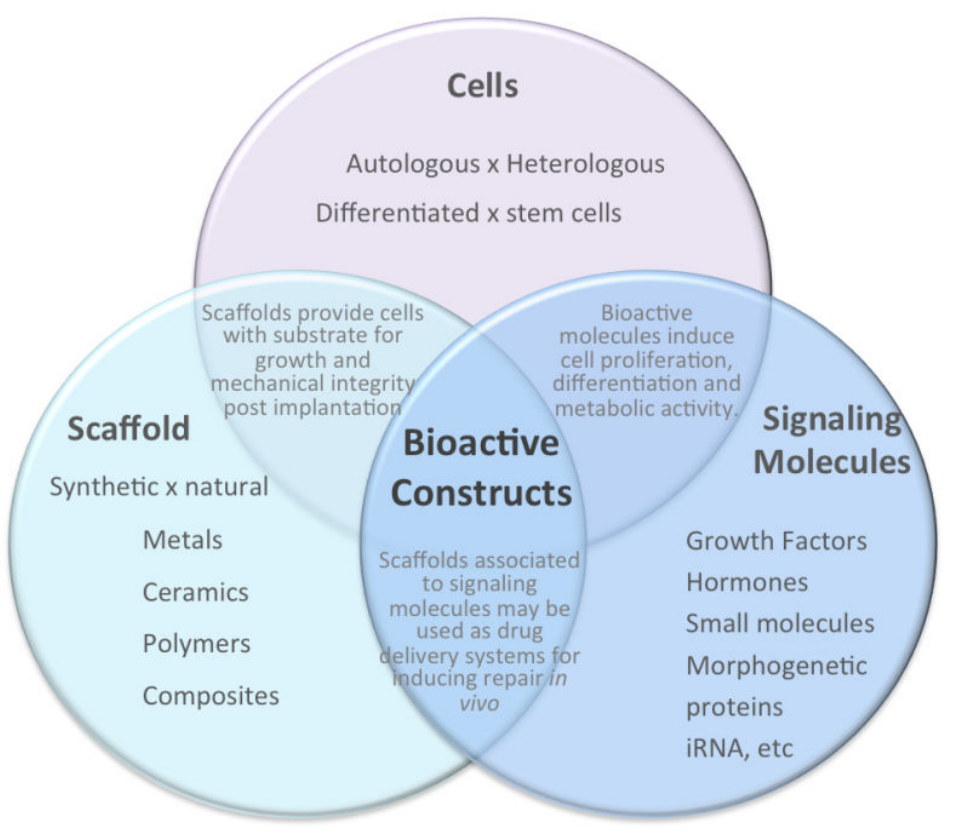

Figure 1. Tissue engineering strategies. Based on [59]. Tissue engineering may be performed by several different approaches, as proposed by Langer and Vancanti. In order to obtain tissue regeneration, cells, scaffolds and signaling molecules may be introduced into the body alone or in association. Currently, the association of all three elements, composing bioactive constructs, is proposed to be the best option for tissue engineering.

In the present chapter, we present the current status of tissue engineering. First, we present a comprehensive picture of classical tissue engineering approaches, as well as an analytic view of its main achievements and limitations. Secondly, we present innovative and paradigm breaking strategies for successful tissue engineering, accompanied by the history and rationale behind each of them. Finally, we analyze the next steps of tissue engineering translation into the clinic.

\section{Classical tissue engineering approaches}

Association of cells to classic biodegradable solid/porous biomaterial represents a dominating conceptual framework in tissue engineering. Actually, men have used biomaterials (alone, not associated to cells) in order to substitute eventual tissue loss since ancient civilizations [11]. In the early days, all kinds of materials derived from natural and manufactured sources were used as biomaterials. Natural materials included wood and shells, and manufactured materials comprised metals such as iron, gold and zinc. The host responses to these materials were extremely varied, and only after the concept of sterility, biomaterial implants began to achieve consistent safety. During the last 30 years, further progress has been made in understanding the interactions between the tissues and the materials. 
Since then, tissue reconstitution evolved to a more sophisticated approach, in which the regeneration of the tissue/organ was clearly viewed as the ideal way of treating injuries, compared to biomaterial science, which simply reconstitutes tissue structure, without restoring tissue function in most situations. This paradigm evolution led to the emergence of tissue engineering.

Tissue engineering based on biomaterials relies on four main classes of materials: i. Polymers, ii. Ceramics, iii. Metals and iv. Composites (blends and combinations of the aforementioned materials). Biomaterials may derive from natural or synthetic sources [12].

The association of cells to biomaterials is called construct and is the base of current tissue engineering, as already stated. Construct-based classic tissue engineering platform derives from several basic assumptions, as described by Mironov et al., 2009 [31]: “1) cell growth is substrate attachment-dependent; cells need a solid substrate for attachment and proliferation; 2) tissue constructs must have an organo-specific shape; a solid scaffold is essential to keep the desired shape; a tissue construct could not maintain its shape without a solid rigid scaffold; 3 ) the scaffold serves not only as an attachment substrate, but also as a source of inductive and instructive signals for cell differentiation, migration, proliferation and orientation; 4) the porous structure of a solid scaffold will allow optimal cell seeding, tissue construct viability, and vascularization; and 5) mechanical properties initially provided by the rigid solid scaffold after its biodegradation will be maintained by controlled neomorphogenesis of parenchymal and stromal tissue synthesized in vitro or in vivo in the tissue construct".

Considering these basic assumptions, currently, classic tissue engineering is made taking several aspects into account, which will be highlighted below.

1. Construct design. Currently, scaffold design is a complex science, in which several aspects are carefully addressed in order to produce successful constructs. Those aspects include, but are not restricted to:

i. Choosing the most suitable biomaterial for the envisioned application. Organs and tissues in the human body present different characteristics, therefore, the ideal biomaterial must reproduce as many as those features as possible. Such aspects include tissue resistance, elasticity, resilience, and chemical composition, among others, in addition to biocompatibility. For instance, a biomaterial designed to be used in a skin construct must be thin and elastic. A biomaterial for application in corneas, on the other hand, must also be thin, but most importantly, it must be transparent.

ii. Customizing the material in order to promote cell colonization. The ideal construct must promote rapid and equal cell adhesion and colonization, therefore scaffolds are usually porous and present a surface which is recognized directly or indirectly (by promoting protein adsorption) by the cell as a substrate for attachment. Usually, materials such as chitosan and collagen are used as biomaterials, due to their resemblance to the extracellularmatrix and theirefficacy in promoting cell adhesion [26,27]. In case of other materials, suchasmetalsand ceramics, biomaterialsurfacemay notbeeasily recognized by cells. In order to improve cell contact and adhesion by cells, many strategies have been developed, such as blending biomaterials, recovering them with other substances or still covering them with protein residues recognized by cells, such as isoleucinelysine-valine-alanine-valine (IKVAV) residue, derived from Laminin [28,29]. 
iii. Studying material tribology and surface topography [19]. For several tissues, such as muscles and tendons, cell organization is paramount for optimal tissue function. The heart, for instance, works as a pumping organ, and needs to contract in a specific, synchronized way in order to actually eject blood into body and lungs. If muscle fibers are not synchronized, no pumping force is generated, and great deficit of function is witnessed by the patient [60]. Tendon is a specific connective tissue composed of parallel collagen fibers. Along with the heart, tendon constitutes another of several tissues which depend on specific cell organization for proper function. It has been thoroughly described in literature that tendon strength is directly linked to cell orientation, and, following injuries, the lack of orientation of scar tissue promotes tendon weakness, leading to repetitive lesion [61]. Tissue engineering approaches for tendon must promote cell alignment in order to achieve significant benefit for patients. cell alignment has been shown to be achievable and effective in promoting tissue organization and maturation [30], as shown in Figure 2.

iv. Optimizing biomaterial degradation rate. Tissue engineering has been envisioned to promote tissue regeneration, therefore in this context, biomaterials should be biodegradable. Ideally, biomaterial should gradually degrade, at the same rate as neotissue is formed.
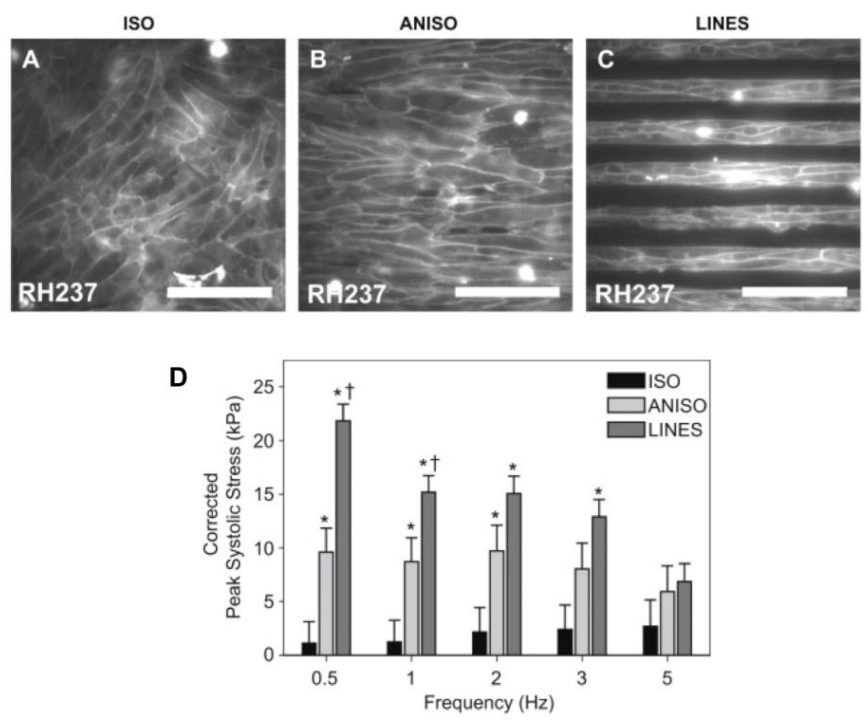

Figure 2. Cell orientation promotes major contractile strength of construct. In order to assess cell orientation importance for construct function, Dr. Parker's group engineered bidimensional cardiac muscles with different micropatterned surfaces in order to promote degrees of cell orientation. Confluent unaligned isotropic (A), aligned anisotropic (B) and non confluent, $20 \mu \mathrm{m}$ spaced, parallel arrays of myocardial fibers (C) were build and studied in vitro. The cited work showed that contractile force increases with major sarcomere alignment, as measured by peak systolic stress in $\mathrm{kPa}(\mathrm{D})$. This panel was based on [60] and was kindly provided by Dr. Kevin Kit Parker, from Harvard University. 
2. Cell seeding. Cell seeding is paramount for construct optimization, and must be carefully planned. Usually, most cells have low capacity of invasion, therefore, cell seeding must be optimized to promote an equal distribution of cells along construct surface and interior [62].

3. Construct maintenance in vitro. The maintenance of small constructs may be achievable in static cultures, but when it comes to larger constructs, static culture is hindered by the limitation of nutrient diffusion. Several strategies have been developed for large construct maintenance in vitro, represented mainly by bioreactors, as depicted in Figure 3.

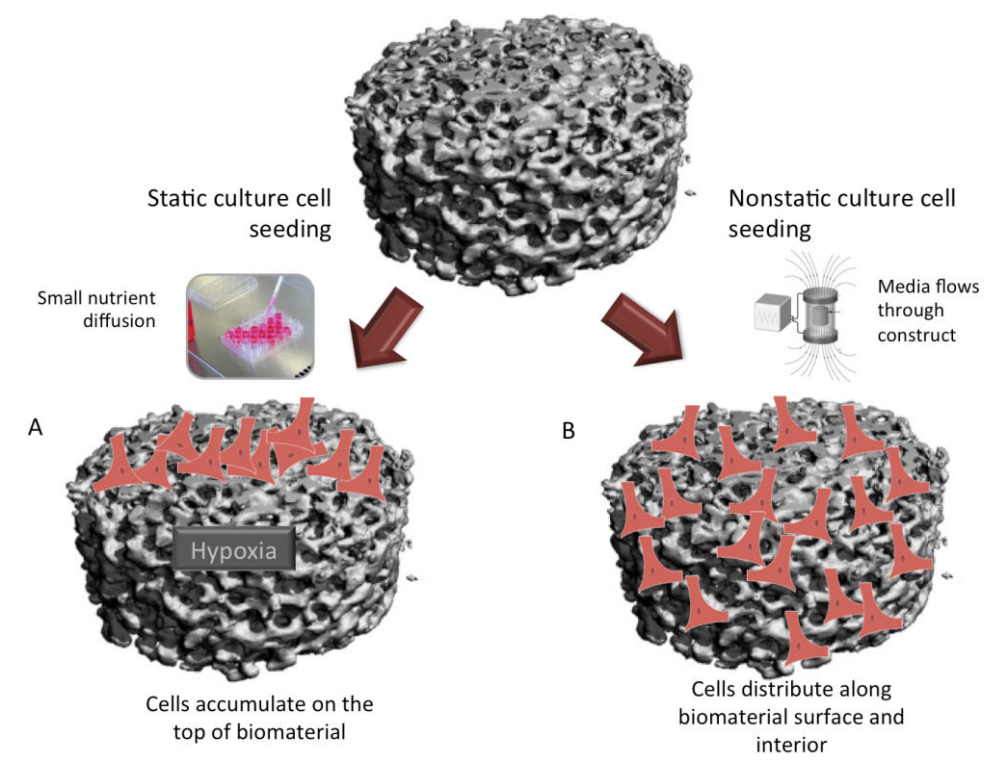

Figure 3. Importance of non-static cell seeding and culture for construct equal distribution of cell elements and viability of construct. As depicted, static culture seeding promotes cell accumulation in specific regions of the construct. As no media is perfused through the construct, nutrient distribution along the biomaterial depends on diffusion only, which leads to normoxic construct edges, colonized with cells and hypoxic center, which is not feasible to be colonized by cells. Nonstatic culture strategies, on the other hand, promote equal cell seeding and colonization of the construct, as it enhances nutrient diffusion. Even though nonstatic culture is not sufficient to promote viability of large constructs, it increases maximum size of constructs and is more adequate for tissue engineering purposes.

4. Construct implant. The ultimate function of a construct built in vitro is to be implanted and substitute/regenerate an injured organ or tissue. Construct implant must be performed in order to promote construct integration and viability. Several techniques have already been applied to promote construct long term viability, such as designing VEGF (vascular endothelial growth factor) releasing constructs; previously implanting the construct in an ectopic site, in order to promote in vivo vascularization, prior to implantation; and reducing the size of implants, among others. 
In spite of its major advances, scaffold-based tissue engineering suffers from several limitations, as explored by Mironov et al., 2009 [31], and further explained here:

1. Vascularization of thick tissue constructs

Cell survival requires continuous supply of nutrients and oxygen, as well as the removal of metabolites, which, if accumulated, might be toxic. Such demand is addressed mainly by osmosis, therefore, to facilitate nutrient and metabolite flow, cells must be kept near vessels and capilars. Actually, few cells are able to survive at more than 200um distance from the nearest blood vessel [8]. Cells cultured in tridimensional scaffolds also need to be maintained in homeostasis in order to survive. In vitro, several strategies have been developed in order to maintain construct viability prior to implantation, mainly through the development of bioreactors, as reviewed by Rauh et. al. [10]. In vivo, however, none of those strategies are applicable, and only through vascularization cells are kept alive, especially for modular organs, such as heart, kidney and liver, which are organized in functioning units and require their own vascular supply [9]. Studies indicate that vessels grow at a rate of $<1 \mathrm{~mm}$ a day [6], and although the effectiveness of an enhanced angiogenic response using various growth factors has been demonstrated in many tissue systems, the rate of angiogenesis hasn 't been accelerated so far [7]. Considering the relatively large sizes of constructs for humans, it is clear the urgent need to promote faster vascularization of tissue constructs, or to improve cell survival in scaffolds.

Actually, several attempts of increasing tissue vascularization are underway.

As previously mentioned, increasing cell survival is also an interesting strategy. Actually, recently, oxygen generating scaffolds have been developed and tested with encouraging results, even though no in vivo tests were performed [7].

2. Precise placing of different multiple cell types inside 3D porous scaffolds is technologically challenging.

Modular organs, such as the heart, liver, kidneys and others, are complex structures of several types of cells, including stromal and parenchymal cells. They function as working units, such as muscle fibers, liver lobules and kidney nephrons. Modular organs also count on intrinsic vascular system for cell survival, constituting incredibly difficult organs to build in vitro, even though many papers have shown a significant capacity of self-organization of several cells $[22,23,24]$. For such organs, whole organ approaches are more suitable then partial reconstitution of those structures.

On the other hand, non-modular organs have witnessed several successful strategies, such as the construction of bladders [44] and the recellularization of tracheas [15], both of which have already been translated to the clinic.

3. Achieving organo-specific level of cell density in tissue constructs remains a big challenge Currently, porous matrices are paramount to allow cell invasion and colonization of the matrix. Porous present in the matrices are usually optimized to have specific sizes and to be interconnected, in order to permit cell invasion. The size of the produced porous is 
usually large, though, and cells within the scaffold are not able to fully fill it and achieve cell density similar to natural tissues. Therefore, it is almost as if cells were still in twodimensional surfaces [31]. Actually, extracellular matrix molecules can be washed out from $3 \mathrm{D}$ porous scaffolds in the same way as in $2 \mathrm{D}$ cultures, and may not provide means for real tridimensional tissue formation.

4. Recent reports on the effect of matrix rigidity on (stem) cell differentiation can undermine the value of solid rigid biodegradable scaffolds at least for certain tissue applications [35-37]

Stem cell differentiation has traditionally employed cocktails of various growth factors, but recently, mechanobiological concepts have been described as important to cell fate decision. The mechanism underlying cellular response to tension comprises the force generated by myosin bundles sliding along actin filaments and transmission to the ECM. Transduction of these signals link the extracellular and intracellular worlds, ultimately affected by proteins such as Rho GTPases, which not only regulate contraction of stress fibers, but also regulate gene expression by acting over their effector target proteins, [45].

Actually, matrix rigidity has been involved in embryonic development, as well as adult stem cell differentiation. As expected, rigid surfaces facilitates adult stem cell differentiation into bone, and soft surfaces lead to differentiation of adult stem cells into soft tissues, such as fat or central nervous system (brain) [45].

5. Biodegradability of constructs

Even though it makes sense that biomaterials should be absorbed by the body in order to give space to neotissue formation, the same is not true when whole tissue engineering is planned. There is no use in spending efforts in order to build a construct, which will be invaded by inflammatory cells and vessels and disorganized, previously to being substituted by neotissue.

Therefore, even though current tissue engineering techniques are fairly successful in treating bone, skin and cartilage loss, they are extremely limited in treating large tissue loss, as well as in regenerating complex tissues, such as heart annd kidneys, among several other tissues and organs.

\section{Innovative tissue engineering approaches}

\subsection{Decellularized matrices}

The Extracellular Matrix (ECM) represents the three-dimensional fibrilar protein scaffold, produced by cells of each tissue and organ, which surrounds and anchors them. It is kept in a state of dynamic reciprocity with those cells, in response to changes in the microenvironment. ECM has been shown to provide cues that affect cell migration, proliferation, gene expression and differentiation [32, 37].

The ECM is obviously the optimal support for tissue engineering, as it provides the perfect chemical composition, surface topology and physical properties experienced by cells in vivo 
in their niche [32]. Even though sometimes that's exactly what is needed to be avoided (e.g. Central Nervous System ECM has been shown to contain molecules which inhibit axonal growth and hinders tissue regeneration $[33,34])$, ECM has been considered a great option for tissue engineering.

Recently, it has been shown that cell sensibility towards ECM chemical composition is higher than previously expected. For instance, Tsai et al. showed that MG63, an osteoblast like cell lineage, behaves differently when grown in collagen or gelatin electrospun matrices. When grown in electrospun collagen, MG63 did not show variation on cell attachment or proliferation rates. On the other hand, cells seeded on electrospun collagen showed increased expression of osteogenic genes such as Osteopontin and alkaline phosphatase. Collagen and gelatin present high chemical composition similarity, varying mainly in secondary and tertiary structure. Such fact underscores the strikingly cell sensitivity to all aspects of ECM chemical and physical composition [62]. It also underscores the potential of decellularized matrices on tissue engineering.

Decellularized tissues have been used in regenerative medicine approaches since the early eighties [38], specially focused on treating cardiovascular diseases by engineering vascular grafts. Most of the grafts produced, derived from synthetic and natural sources suffered from several limitations. When the issue of natural graft calcification and immunological recognition were related to residual cellular components of unmodified biological materials, decellularization techniques began to be developed $[38,39]$.

Initially, decellularization was considered for tissue grafts. Developed techniques are continuously evolving, as every cell removal agent and method currently available alters ECM composition and cause some degree of ultrastructure disruption. Decellularization agents include chemical, biological and physical agents, each of them with different mechanisms of action.

More specifically: acids and bases promote hydrolytic degradation of biomolecules; hypotonic solutions lyses cells through osmosis with minimal changes in matrix molecules and tissue architecture; hypertonic solutions dissociates DNA from proteins; ionic, non-ionic, and zwitterionic detergents solubilize cell membranes leading to effective removal of cellular material from tissue; solvents, such as alcohol and acetone, promote either cell lysis by dehydration or solubilization and removal of lipids and biological agents, such as enzymes, and chelating agents act through protein cleavage and disrupting cell adhesion to ECM. Finally, physical agents promote cell lysis through freezing and thawing cycles, electroporation or pressure [32].

The most effective agents for decellularization of each tissue and organ will depend upon many factors, including the tissue's cellularity, density, lipid content, and thickness [32].

Lately, whole organ decellularization began to be performed, offering an interesting option for modular organs such as the heart, lung and kidneys. In 2008, Ott et al. not only performed whole heart decellularization, but also recellularized the organ with neonatal cardiomyocytes and obtained organ function [17]. This groundbreaking work highlighted the possibilities of decellularized matrix-based whole organ tissue engineering. 
The major breakthrough of organ decellularization is to obtain scaffolds with perfect (or very similar) chemical composition and tridimensional structure, compared to natural organs. In addition, the vascular bed is completely preserved, facilitating in vitro maintenance of the construct via perfusion bioreactors, as well as in vivo viability of the construct, which may be reconnected to the circulatory system of host, also shown by Ott et al [17]. As decellularization is performed making use of vascular system of organs, virtually any vascularized organ may be decellularized, disregarding its size, as depicted in Figure 4. Acellular organs, such as tracheas, may also be decellularized through different protocols [15].

\section{Perfusion Decellularization Results in Exquisite Retention of Structure}

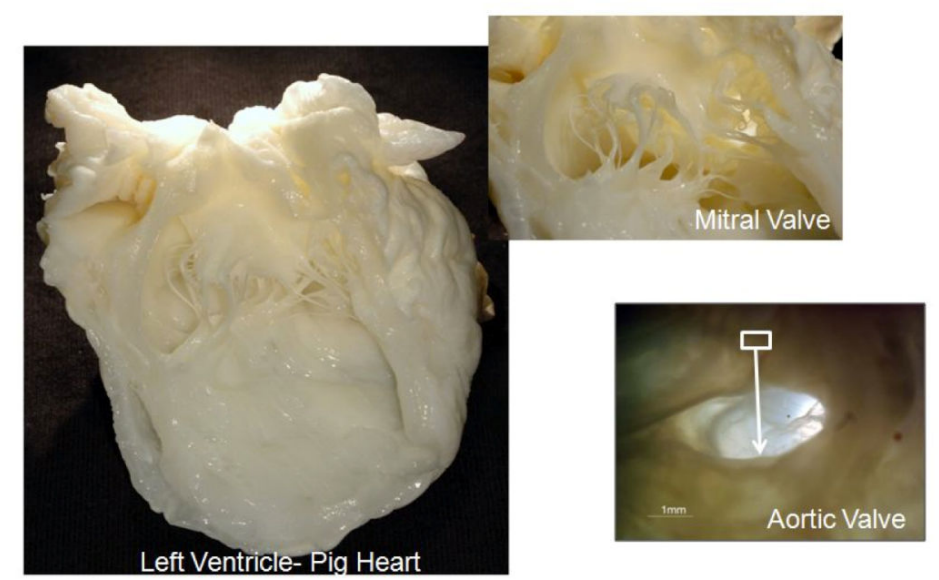

Figure 4. Decellularized pig heart. As published by Ott et al., perfusion decellularization is feasible in small rat organs, but also in bigger size organs, such as the pig heart. Illustration owned by Miromatrix Medical Inc., available at http:// miromatrix.com/technology/perfusion-decellularization-recellularization/, accessed on September 2012.

\subsection{Biomimetic scaffolds}

As already mentioned, an optimal scaffold attempts to mimic the function of the natural extracellular matrix [52]. The functionality of most tissues is related to their complex architecture, therefore mimicking and recapitulating this complexity in vitro is paramount for successful tissue engineering. In the in vivo condition, cells are surrounded by other cells and by the extracellular matrix (ECM), whose components, such as collagen, elastin, and laminin, are organized in nanostructures (i.e., fibers, triple helixes, etc) with specific bioactive motifs that regulate cell homeostasis [42].

Following the initial concept of mimicking the ECM chemical composition, it has been shown that the structure of the cell-surrounding niche is also paramount for optimal cell function. In accordance, modulating the scaffold microarchitecture is one of the most potent ways of 
achieving biomimetic tissues. Advances in microfabrication technologies have been exploited by an increasing number of research groups. Often technologies from other engineering disciplines have been translated and used in creating microfeatures in engineered scaffolds in a controlled manner. These include photolithographic approach of the electrical engineering, electrospinning tools of the textile industry, emulsification and fluid dynamics principles of chemical engineering and rapid prototyping methods of mechanical engineering. The latter will be covered in further detail in the next section [40].

Vacanti and coworkers pioneered the concept of engineering a vasculature using photolithographic techniques (which use light, e.g. UV, to selectively remove parts of a thin film or the bulk of a substrate), literally generating channels within biomaterials [43].

Electrospining techniques have also been considered and tested for tissue engineering application, due to their potential of producing polymer fibers with nano to micrometer diameter scale that are physically and topographically comparable to the collagen fibers, commonly found in the natural ECM, as shown in Figure 5. It has been extensively employed in tissue engineering strategies, including vascularization strategies [41].
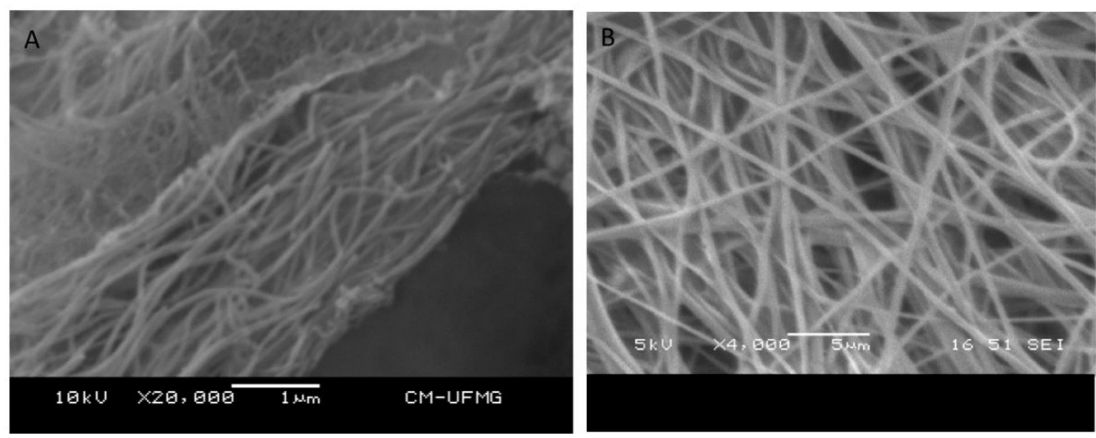

Figure 5. Similarity between ultrastructure of natural collagen fibers (A) and electrospun biomaterials (B). Source: A author's unpublished data; B - http://en.wikipedia.org/wiki/Electrospinning, accessed on September 2012.

Electrospun biomaterials must also be carefully fabricated, as even fiber diameter variation results in different cell behavior, as observed in endothelial cells cultured on electrospun poly(l-lactide-co- $\varepsilon$-caprolactone) with different fiber diameters. In contrast to cells cultured on fibers of 0.3 or $1.2 \mu \mathrm{m}$, cells cultured on $7 \mu \mathrm{m}$ presented lower cell adhesion, spreading and proliferation [63].

Even though electrospining has presented promising results, it also suffers from some limitations, such as poor cell invasion, as usually the electrospun biomaterials are highly compacted, impeding cell migration towards the inner side of the scaffold. The search for different solvents and electrospining conditions may solve this issue, promoting less fiber compactation. 
Still, as cited, many excellent constructs have been built using those techniques, and in association with the other tissue engineering strategies presented in the present chapter, strongly contribute to novel advances in the field.

Another exciting tissue engineering strategy, which have gained growing interest since the nineties, has been the hydrogel approach. Hydrogels are 3D cross-linked insoluble, hydrophilic networks of polymers that partially resemble the physical characteristics of native ECM. The biocompatibility of various hydrogels (e.g., collagen, agarose and polyethylene glycol) is well characterized, and the possibility of optimizing their physico-chemical and mechanical properties to levels that are desirable for tissue scaffolds, in order to achieve cell encapsulation, immobilization, and drug delivery turn hydrogels into an extremely promising technique [64].

Hydrogels have been successfully used in mimicking ECM of simple tissues, composed of one cell type. In many cases, hydrogels provide means for nutrient diffusion, facilitating cell maintenance in vitro and in vivo. Still, maintaining the viability of high cell density constructs remains a challenge as well as promoting cell organization within the scaffold. In many cases, construct implantation near host rich vascularization sites may be an effective strategy to promote construct viability in vivo.

In the cell's point of view, hydrogels possess the advantage of completely surround encapsulated cells, and providing tridimensional substrate for cell interaction. This strategy prevents cell polarization which is common to regular scaffolds. Usually, as already stated, even though most scaffolds may be tridimensional macroscopically, they are commonly seen as bidimensional surfaces by cells.

As expected, truly tridimensional environments promote several effects over cultured cells. Some of them include, but are not limited to: cell morphology/spreading [65], cell motility and proliferation [66], and metabolic rate [67]. Obviously, all of those cell behaviors reflect differential gene expression.

Even though cell gene expression is a paramount factor to be evaluated in tissue engineering, it must be clearly noted that an exact gene expression profile is not essential for tissue engineering effectiveness. Cells will always interact with their microenvironment. What is important for tissue engineering is to maintain cell plasticity in a manner that, once in vivo, implanted cells start to behave as host cells would.

Finally, a third highly modern and innovative approach for tissue engineering, which shares the truly tridimensional environment for cells as provided by hydrogels, but which doesn 't suffer from vascularization and cell organization limitations presented by the latter, is the organ printing tissue engineering technique, which will be more thoroughly described in the next section.

\subsection{Organ printing}

As listed before, the main limitations of the solid scaffold approach include the low level of precision in cell placement, especially when engineering multicellular constructs, considering 
the intrinsic problem of vascularization of thick tissue constructs [53]. Ideally, a possible way to solve many of those aforementioned problems would be to assemble cells and ECM elements at the same time and in an organized way, in order to obtain the most similar structure found in a functional organ as possible. Over the years, technology evolution turned tissue engineers unreachable dream into a feasible objective to be fulfilled in the next years or decades. This strategy is known as organ printing and/or robotic biofabrication, and offer interesting alternatives to solid scaffold-based tissue engineering.

According to the First International Workshop on Bioprinting and Biopatterning, organ printing was defined as "The use of material transfer processes for patterning and assembling biologically relevant materials (molecules, cells, tissues, and biodegradable biomaterials) with a prescribed organization to accomplish one or more biological functions" [45]. In fact, this technology could be defined as computer-aided, layer-by-layer deposition of biologically relevant materials [53].

The ultimate goal of organ-printing technology is to fabricate 3D vascularized functional living human organs suitable for clinical implantation in reasonable time scales. Other applications of this technology are in histogenesis and organogenesis, pharmacological tests and disease research $[45,46,47,48]$.

Wilson and Boland (2003) showed protein and cell printing using a commercial ink-jet device can be possible. In this technology, either individual cells or small clusters are printed over ECM hydrogels, designed for involve printed cells and to provide them with desired signals. Therefore, organ printing has derived from hydrogel classical approach, described in the previous section. The method is rapid, versatile and cheap. Its disadvantage is that it is difficult to assure high cell density needed for the fabrication of solid organ structures. Furthermore, due to the high speed of cell deposition, considerable damage is caused to cells, although the latest developments in the field have led to considerable improvement in cell survival [54, 55]. In the other approach, mechanical extruders are used to place 'bio-ink' particles, multicellular aggregates of definite composition into a supporting environment, the 'biopaper', according to computer-generated templates consistent with the topology of the desired biological structure. Organoids are formed by postprinting fusion of the bio-ink particles and the sorting of cells within the bio-ink particles. The advantage of this technology is that the bio-ink particles represent small 3D tissue fragments. Thus, cells in them are in a more physiologically relevant arrangement, with adhesive contacts with their neighbors, which may assure the transmission of vital molecular signals. Both inkjet and extruder bioprinting are compatible with rapid prototyping [55].

In this biomanufacturing a precise layer-by-layer placement of self-assembled tissue spheroids in sprayed tissue fusion permissive hydrogels is used to obtain an organ or tissue. The hydrogels work as "biopapers" and cell blocks or tissue spheroids work as a "bioink". Both biopaper and bioink must be optimized in order to obtain viable tissues. For instance, biopapers vary according to each "printed" organ, and cell spheroids vary in properties according to their composition. Cell viability during and after printing is an obvious goal for bioprinting [45]. Preliminary studies of both ink-jet and laser forward transfer indicated that cells can survive deposition condition forces. Problems associated with ink-jet delivery of cell 
suspensions may also come about from the high shear stresses observed during ejection and impact of a fluid drop [50, 51, 52].

In many cases, the bioprinting process requires that before and during printing, cells and molecules must be carried in a fluid vehicle that shortly after printing requires consolidation and should consequently behave as a viscoelastic solid. This phase change must occur without damage to the biochemical, cells, or more complex units within the fluid, which presents a considerable challenge. Concurrently, tissue printed mustn't be too solid, or cell spheroids won't interact and form a continued tissue.

Organ printing is a technology that promises to transform tissue engineering into a commercially successful biomedical industry. Unlike other tissue engineered approaches, organ printing involves the high throughput generation of organs, relying on automated cell sorters, cell and organ bioreactors and robotic bioprinters, most of them which are already commercially available [46]. However, much research is necessary to turn this technology into reality of clinical application.

\section{Conclusion: Tissue engineering - From the bench to the bedside}

It is known that any technology takes about 20 years to reach the market, and despite progress in many fields, this timeframe has yet to shorten [20]. Accordingly, tissue engineering, which has officially given its first steps during the late eighties, hasn 't brought many products to the bedside [20].

In contrast to biomaterials - which are readily available as hip implants, contact lenses, silicon breast prosthesis, among others -, and cell therapy - which is also available for bone marrow transplants, as well as its first allogeneic stem cell therapy products [21] -, constructs have been successfully produced for only few applications, largely limited to non-modular organs such as skin epidermis, corneal epithelium and cartilage [40]. Indeed, Apligraf - a bilayered skin substitute - was the first allogeneic cell based therapy to be approved by the US Food and Drug Administration (FDA), receiving permission for sale as a treatment for venous leg ulcers13.

Apligraf is constructed by culturing human foreskin-derived neonatal fibroblasts in a bovine type I collagen matrix over which human foreskin-derived neonatal epidermal keratinocytes are then cultured and allowed to stratify [68]. Even though it is considered one of the first tissue engineering products ever approved for commercialization, Apligraf doesn `t directly restore skin, but transiently protects and provides injured skin with scaffold and signaling molecules (produced by the cells within the construct) which fosters and accelerate skin regeneration.

Engineered bladders and airways have also been built and implanted in vivo, but as they require highly customized and complex approaches, they are available to a small number of patients, and are not considered products to be sold, such as Apligraf and other similar products.

Therefore, it is clear that, in spite of recent advances, tissue engineering has much to deliver. Innovative strategies, such as the presented in this chapter, present out of the box solutions 
for some of the present challenges in the field, and may one day constitute the major breakthroughs to finally catalyze translating tissue engineering from bench to bedside.

\section{Author details}

Juliana Lott Carvalho ${ }^{1}$, Pablo Herthel de Carvalho ${ }^{2}$, Dawidson Assis Gomes ${ }^{1}$ and Alfredo Miranda de Goes ${ }^{1}$

*Address all correspondence to: julianalott@gmail.com

1 Department of Biochemistry and Immunology, Federal University of Minas Gerais, Belo Horizonte, Brazil

2 Department of Veterinary Clinicals and Surgery of the Federal University of Minas Gerais, Belo Horizonte, Brazil

\section{References}

[1] Skalak R, Fox CF. Tissue engineering. New York: Liss; 1988.

[2] Lanza RP, Langer R, Vacanti J. Principles of tissue engineering. $3^{\text {rd }}$ edition. Elsevier Inc; 2007

[3] Langer RL, Vacanti JP. Tissue Engineering. Science 1993; 260(5110) 920-926.

[4] National Institutes of Aging. Why population aging matters - A global perspective. http://www.nia.nih.gov/research/publication/why-population-aging-matters-globalperspective (accessed 18 july 2012).

[5] Song JJ, Ott HC. Organ engineering based on decellularized matrix scaffolds. Trends in Molecular Medicine 2011. Article in press. doi:10.1016/j.molmed.2011.03.005.

[6] Mikos AG, Sarakinos G, Ingber DE, Vacanti J, Langer R. Prevascularization of porous biodegradable polymers. Biotech Bioengineering 1993; 42(6) 716-23.

[7] Oh SH, Ward CL, Atala A, Yoo JJ, Harrison BS. Oxygen generating scaffolds for enhancing engineered tissue survival. Biomaterials 2009; 30(5) 757-762).

[8] Kaully T, Kaufman-Francis K, Lesman A, Levenberg S. Vascularization--the conduit to viable engineered tissues. Tissue Eng Part B Rev. 2009; 15(2) 159-69.

[9] Alberti C. Hollow organ tissue engineering: short updating about current approaches and forecast for major research advances. Giornal e Chirurgia 2011; 32(8-9) 345-351.

[10] Rauh J, Milan F, Günther KP, Stiehler M. Bioreactor systems for bone tissue engineering. Tissue Eng Part B Rev. 2011; 17(4) 263-80. 
[11] Williams DF, Cunningham J. Materials in Clinical Dentistry. Oxford; Oxford University Press, 1979.

[12] Ratner BD. Biomaterials Science: An Introduction to Materials in Medicine. London: Elsevier Academic Press, 2004

[13] Pham C, Greenwood J, Cleland H, Woodruff P, Maddern G. Bioengineered skin substitutes for the management of burns: a systematic review. Burns 2007; 33(8) 946-57

[14] Burchill LJ, Ross HJ. Heart transplantation in adults with end-stage congenital heart disease. Future Cardiol. 2012; 8(2) 329-42.

[15] Macchiarini P, Jungebluth P, Go T, Asnaghi MA, Rees LE, Cogan TA, Dodson A, Martorell J, Bellini S, Parnigotto PP, Dickinson SC, Hollander AP, Mantero S, Conconi MT, Birchall MA. Clinical transplantation of a tissue-engineered airway. The Lancet 2008; 372: 2023-30.

[16] Molzahn AE, Starzomski R, McCormick J. The supply of organs for transplantation: issues and challenges. Nephrol Nurs J. 2003;30(1) 17-26.

[17] Ott HC, Matthiesen TS, Goh SK, Black LD, Kren SM, Netoff TI, Taylor DA. Perfusiondecellularized matrix: using nature's platform to engineer a bioartificial heart. Nat Med. 2008; 14(2) 213-21.

[18] U.S. Organ Procurement and Transplantation Network and the Scientific Registry of Transplant Recipients. 2009 OPTN / SRTR Annual Report: Transplant Data 1999-2008. http://www.ustransplant.org/annual_Reports/current/default.html (accessed 2 august 2012).

[19] Chaureya V, Blocka F, Sua YH, Chiang PC, Botchweyc E, Choub CF, Swamia NS. Nanofiber size-dependent sensitivity of fibroblast directionality to the method of alignment of the scaffold. Acta Biomaterialia 2012. Epub ahead of print.

[20] Future Directions in Regenerative Medicine. Business Insights, February 2012.

[21] Osiris therapeutics, Press release: Osiris Therapeutics Reports Second Quarter 2012 Financial Results. http://investor.osiris.com/ (accessed 6 august 2012).

[22] Wei C, Larsen M, Hoffman MP, Yamada KM. Self-organization and branching morphogenesis of primary salivary epithelial cells. Tissue Eng. 2007;13(4) 721-35.

[23] Takebe T, Sekine K, Suzuki Y, Enomura M, Tanaka S, Ueno Y, Zheng YW, Taniguchi H. Self-organization of human hepatic organoid by recapitulating organogenesis in vitro. Transplant Proc. 2012; 44(4) 1018-20.

[24] Takebe T, Koike N, Sekine K, Enomura M, Chiba Y, Ueno Y, Zheng YW, Taniguchi H. Generation of functional human vascular network. Transplant Proc. 2012; 44(4) 1130-3.

[25] Green JB, Dominguez I, Davidson LA. Self-organization of vertebrate mesoderm based on simple boundary conditions. Dev Dyn. 2004; 231(3) 576-81. 
[26] Miranda SC, Silva GA, Mendes RM, Abreu FA, Caliari MV, Alves JB, Goes AM. Mesenchymal stem cells associated with porous chitosan-gelatin scaffold: A potential strategy for alveolar bone regeneration. J Biomed Mater Res A. 2012. doi: 10.1002/jbm.a. 34214. [Epub ahead of print]

[27] Miranda SC, Silva GA, Hell RC, Martins MD, Alves JB, Goes AM. Three-dimensional culture of rat BMMSCs in a porous chitosan-gelatin scaffold: A promising association for bone tissue engineering in oral reconstruction. Arch Oral Biol. 2011; 56(1) 1-15.

[28] Ding T, Luo ZJ, Zheng Y, Hu XY, Ye ZX. Rapid repair and regeneration of damaged rabbit sciatic nerves by tissue-engineered scaffold made from nano-silver and collagen type I. Injury. 2010; 41(5) 522-7.

[29] X. Lin, K. Takahashi, Y. Liu, P.O. Zamora. Enhancement of cell attachment and tissue integration by a IKVAV containing multi-domain peptide. Biochimica et Biophysica Acta 2006; 1760(9) 1403-1410.

[30] Choi JS, Lee SJ, Christ GJ, Atala A, Yoo JY. The influence of electrospun aligned poly( $\varepsilon-$ caprolactone)/collagen nanofiber meshes on the formation of self-aligned skeletal muscle myotubes. Biomaterials 2008; 29(19), 2899-2906.

[31] Mironov V, Visconti RP, Kasyanov V, Forgacs G, Drake CJ, Markwald RR. Organ printing: tissue spheroids as building blocks. Biomaterials 2009; 30(12) 2164-74.

[32] Crapo PM, Gilbert TW, Badylak SF. An overview of tissue and whole organ decellularization processes. Biomaterials 2011; 32(12) 3233-3243.

[33] Giger RJ, Hollis ER, Tuszynski MH. Guidance molecules in axon regeneration. Cold Spring Harb Perspect Biol. 2010; 2(7) a001867.

[34] Sharma K, Selzer ME, Li S. Scar-mediated inhibition and CSPG receptors in the CNS. Exp Neurol. 2012. [Epub ahead of print]

[35] Parka JS, Chua JS, Tsou AD, Diopa R, Tanga Z, Wang A, Li S. The effect of matrix stiffness on the differentiation of mesenchymal stem cells in response to TGF-b. Biomaterials 2011; 32 3921-3930.

[36] Chaudhuri O, David J. Mooney. Stem-cell differentiation: Anchoring cell-fate cues. Nature Materials 2012; 11 568-569.

[37] Reilly GC, Engler AJ, Intrinsic extracellular matrix properties regulate stem cell differentiation. Journal of Biomechanics 2010; 43(1) 55-62.

[38] Malone JM, Brendel K, Duhamel RC, Reinert RL. Detergent-extracted small-diameter vascular prostheses. Journal of Vascular Surgery 1984. 1(1) 181-194.

[39] Schmidt CE, Baier JM. Acellular vascular tissues: natural biomaterials for tissue repair and tissue engineering. Biomaterials 2000; 21(22) 2215-31. 
[40] Zorlutuna P, Annabi N, Camci-Unal G, Nikkhah M, Cha JM, Nichol JW, Manbachi A, Bae H, Chen S, Khademhosseini A. Microfabricated Biomaterials for Engineering 3D Tissues. Advanced Biomaterials 2012; 4 1782-1804.

[41] Zonari A, Novikoff S, Electo NRP, Breyner NM, Gomes DA, et al. Endothelial Differentiation of Human Stem Cells Seeded onto Electrospun Polyhydroxybutyrate/ Polyhydroxybutyrate-Co-Hydroxyvalerate Fiber Mesh. PLoS ONE 2012; 7(4) e35422. doi:10.1371/journal.pone.0035422

[42] Perán M, García MA, López-Ruiz E, Bustamante M, Jiménez G, Madeddu R, Marchal JA. Functionalized Nanostructures with Application in Regenerative Medicine. Int. J. Mol. Sci. 2012; 13 3847-3886.

[43] Kaully T, Kaufman-Francis K, Lesman A, Levenberg S. Vascularization: The Conduit to Viable Engineered Tissues. Tissue Eng Part B Rev. 2009; 15(2) 159-169.

[44] Atala A, Bauer SB, Soker S, Yoo JJ, Retik AB. Tissue-engineered autologous bladders for patients needing cystoplasty. Lancet 2006; 367(9518) 1241-1246.

[45] Mironov V, Reis N, Derby B. Bioprinting: A Beginning. Tissue Engineering 2006; 12(4) 631-634.

[46] Mironov V, Kasyanov, V, Markwald RR. Organ printing: from bioprinter to organ biofabrication line. Current Opinion in Biotechnology 2011; 22 667-673.

[47] Mironov V, Trusk T, Kasyanov, Little S, Swaja R, Markwald RR. Biofabrication: a 21st century manufacturing paradigm. Biofabrication 2009; 1 1-16.

[48] Partridge R, Conlisk N, Davies JA. In-lab three-dimensional printing. An inexpensive tool for experimentation and visualization for the field of organogenesis. Organogenesis 2012; 8(1) 22-27.

[49] Lalan S, Pomerantseva I, Vacanti JP. Tissue engineering and its potential impact on surgery. World Journal of Surgery 2001; 25 1458-1466.

[50] Mironov V, Boland T, Trusk T, Forgacs G, Markwald RR. Organ printing: computeraided jet-based 3D tissue engineering. TRENDS in Biotechnology 2003; 21(4) 157-161.

[51] Mironov V, Visconti RP, Kasyanov V, Forgacs G, Drake CJ, Markwald RR. Organ printing: tissue spheroids as building blocks. Biomaterials 2009; 30 2164-2174.

[52] Yeong WY, Chua CK, Leong KF, Chandrasekaran M. Rapid prototyping in tissue engineering: challenges and potential. TRENDS in Biotechnology, 22(12) 663-662.

[53] Mirononv V, Kasyanov V, Drake C, Markwald RR. Organ printing: promises and challenges. Regenerative Medicine 2008; 3(1) 93-103.

[54] Wilson WC, Boland T. Cell and organ printing 1: protein and cell printers. The Anatomical Record Part A 2003; 272 491-496. 
[55] Jakab K, Norotte C, Marga F, Murphy K, Vunjak-Novakovic G, Forgacs G. Tissue engineering by self-assembly and bio-printing of living cells. Biofabrications 2010; 2 $1-14$.

[56] Assis AC, Carvalho JL, Jacoby BA, Ferreira RL, Castanheira P, Diniz SO, Cardoso VN, Goes AM, Ferreira AJ. Time-dependent migration of systemically delivered bone marrow mesenchymal stem cells to the infarcted heart. Cell Transplantation 2010;19(2) 219-30.

[57] Kumar S, Ponnazhagan S. Mobilization of bone marrow mesenchymal stem cells in vivo augments bone healing in a mouse model of segmental bone defect. Bone 2012; 50(4) 1012-8.

[58] Liu Z, Yang D, Xie P, Ren G, Sun G, Zeng X, Sun X. MiR-106b and MiR-15b modulate apoptosis and angiogenesis in myocardial infarction. Cell Physiol Biochem 2012; 29(5-6) 851-62.

[59] Daher JD, Chahine NO, Greenberg AS, Sgaglione NA, Grande DA. New methods to diagnose and treat cartilage degeneration. Nature Reviews Rheumatology 2009; 5 599-607.

[60] Feinberg AW, Alford PW, Jin H, Ripplinger CM, Werdich AA, Sheehy SP, Grosberg A, Parker KK. Controlling the contractile strength of engineered cardiac muscle by hierarchal tissue architecture. Biomaterials 2009; 33(23) 5732-5741.

[61] Wang JH, Jia F, Gilbert TW, Woo SL. Cell orientation determines the alignment of cellproduced collagenous matrix. J Biomech. 2003; 36(1) 97-102.

[62] Tsai SW, Liou HM, Lin CJ, Kuo KL, Hung YS, Weng RC, Hsu FY. MG63 osteoblast-like cells exhibit different behavior when grown on electrospun collagen matrix versus electrospun gelatin matrix. PLoS One 2012; 7(2) e31200.

[63] Kwon IK, Kidoaki S, Matsuda T. Electrospun nano- to microfiber fabrics made of biodegradable copolyesters: structural characteristics, mechanical properties and cell adhesion potential. Biomaterials 2005; 26(18) 3929-39.

[64] Geckil H, Xu F, Zhang X, Moon S, Demirci U. Engineering hydrogels as extracellular matrix mimics. Nanomedicine 2010; 5(3) 469-484.

[65] Burdick JA, Vunjak-Novakovic G. Engineered microenvironments for controlled stem cell differentiation. Tissue Eng Part A. 2009; 15(2) 205-19.

[66] Tibbitt MW, Anseth KS. Hydrogels as extracellular matrix mimics for 3D cell culture. Biotechnol Bioeng. 2009; 103(4) 655-63.

[67] Zahir N, Weaver VM. Death in the third dimension: apoptosis regulation and tissue architecture. Current Opinion in Genetics and Development 2004; 14(1) 71-80.

[68] Zaulyanov L, Kirsner RS. A review of a bi-layered living cell treatment (Apligraf) in the treatment of venous leg ulcers and diabetic foot ulcers. Clin Interv Aging 2007; 2(1) 93-8. 
